\title{
Impact of a training course on the quality of malaria diagnosis by microscopy in Angola
}

\author{
Sofia Moura ${ }^{1}$, Cláudia Fançony ${ }^{1}$, Clara Mirante ${ }^{1}$, Marcela Neves² ${ }^{2}$ Luís Bernardino², Filomeno Fortes ${ }^{3}$,
} Maria do Rosário Sambo ${ }^{4}$ and Miguel Brito ${ }^{1,5^{*}}$

\begin{abstract}
Background: In Angola, malaria is an endemic disease having a major impact on the economy. The WHO recommends testing for all suspected malaria cases, to avoid the presumptive treatment of this disease. In malaria endemic regions laboratory technicians must be very comfortable with microscopy, the golden standard for malaria diagnosis, to avoid the incorrect diagnosis. The improper use of medication promotes drug resistance and undesirable side effects. The present study aims to assess the impact of a three-day refresher course on the knowledge of technicians, quality of blood smears preparation and accuracy of microscopy malaria diagnosis, using qPCR as reference method.
\end{abstract}

Methods: This study was implemented in laboratories from three hospitals in different provinces of Angola: Bengo, Benguela and Luanda. In each laboratory samples were collected before and after the training course (slide with thin and thick blood smears, a dried blood spot and a form). The impact of the intervention was evaluated through a written test, the quality of slide preparation and the performance of microscopy.

Results: It was found a significant increase on the written test median score, from 52.5\% to 65.0\%. A total of 973 slides were analysed to evaluate the quality of thick and thin blood smears. Considering all laboratories there was a significant increase in quality of thick and thin blood smears. To determine the performance of microscopy using qPCR as the reference method we used 1,028 samples. Benguela presented the highest values for specificity, $92.9 \%$ and 98.8\% pre and post-course, respectively and for sensitivity the best pre-course was Benguela (75.9\%) and post-course Luanda (75.0\%). However, no significant increase in sensitivity and specificity after the training course was registered in any laboratory analysed.

Discussion: The findings of this study support the need of continuous refresher training for microscopists and other laboratory staff. The laboratories should have a quality control programme to supervise the diagnosis and also to assess the periodicity of new training. However, other variables needed to be considered to have a correct malaria diagnosis, such as adequate equipment and reagents for staining and visualization, good working conditions, motivated and qualified personnel.

Keywords: Malaria, Training, Angola, Impact, Microscopy, Quality

\section{Background}

In Angola, malaria affects mostly children under five, and it is estimate that this disease is responsible for $60 \%$ of hospital admissions and $35 \%$ of mortality at this age group $[1,2]$. Malaria misdiagnosis is an important cause of additional morbidity and mortality. The World Health

\footnotetext{
* Correspondence: miguel.brito@estesl.ipl.pt

'Health Research Centre of Angola (CISA), Caxito, Angola

5 Lisbon School of Health Technology, Lisbon, Portugal

Full list of author information is available at the end of the article
}

Organization (WHO) guidelines recommend biological confirmation of all suspected malaria patients by microscopy or alternatively by rapid diagnostic tests (RDTs). Presumptive treatment is no longer recommended unless diagnostic tests are not accessible [3]. Accurate malaria diagnosis is essential to a successful and sustainable malaria control as it improves patient care (by reducing the misdiagnosis and therefore inadequate treatment of malaria infections and other febrile diseases), reduces the non-rational drug use that can lead to drug resistance 
[3-5] and enhances the quality of surveillance, preventing the distortion of statistics, misinformed interventions and economic loss [4-6]. A study carried out in Angola [7] found evidence that health workers resist to laboratory results (mostly negative ones) mainly due to the lack of trust in the performed tests.

Microscopy is the reference standard to diagnose malaria and it allows detection, identification of species and quantification of the parasitaemia [8-10]. WHO highlights that the recommended sensitivity for this method ( $95 \%$ at a parasite density of $100 / \mu \mathrm{l}$ ) is achievable in highquality reference laboratories but hard to establish in laboratories from peripheral hospitals and health centres in malaria-endemic countries [11]. Consequently, the quality of results varies considerably from one lab to another, mainly due to the level of expertise of microscopists, quality of reagents and equipment, employed techniques, workload capacity and inefficient quality control procedures $[8,12]$. In turn, limited training and supervision of microscopists often leads to unfamiliarity with the different forms of species other than Plasmodium falciparum, inaccurate estimative of parasite density, underreported mixed infections and difficulty in detecting cases with low parasitaemia $[13,14]$. However, microscopy can reach high performance standards when manned by competent and motivated individuals, supported by effective training and supervision and adequate supply of reagents and equipment [8]. Studies have been made using short training courses and while some showed an increase in knowledge of staff $[15,16]$, accuracy of microscopy, quality of blood slide preparation $[15,17]$ and a reduction in specie misclassification [18] others showed no improvement in the quality of malaria diagnosis $[19,20]$.

Despite that PCR is mostly used in research scenarios due to its high cost and required laboratorial infrastructure, it is easily reproducible and highly optimized for sensitivity (detecting low parasitaemia cases and accurately differentiating the Plasmodium species) being used in surveillance as a performance measurer of microscopy [21-23].

This study, conducted in three health facilities from different provinces of Angola, aimed to evaluate the performance of microscopy on the diagnosis of malaria in children using real time PCR (qPCR) as reference method. Additionally, the impact of a three-day refresher course on the performance of microscopists and, therefore, on the quality of microscopy diagnosis, was evaluated.

\section{Methods}

\section{Study area}

Angola has 18 provinces and the capital city is Luanda. In terms of transmission this country is divided into hyperendemic, mesoendemic with stable transmission and mesoendemic with unstable transmission areas [1]. This study was implemented in three laboratories from hospitals in three different provinces of Angola: Bengo, Benguela and Luanda, all belonging to the mesoendemic area with stable transmission. At each hospital the samples were collected from the emergency paediatric department. This study was developed together with the Angola National Malaria Control Programme (ANMCP) and ethical approval for the study was obtained from the Angolan Ministry of Health Ethics Committee.

\section{Intervention}

The training intervention consisted of a three-day refresher course based on WHO training manual [24] and included lectures and practical hands-on sessions on malaria disease, epidemiological data, cleaning and storage of slides, preparation of thick and thin blood films, Giemsa staining, correct use and care of the microscope, examination of blood films and correct identification of Plasmodium species [24]. The training courses were implemented, at the laboratories involved in this study, by one technician from the ANMCP and one expert microscopist from Health Research Centre of Angola (CISA Project) from December 2012 to March 2013. It was given a manual for each participant with a colour atlas of the different Plasmodium species, so that they could take notes during the course and use it in their laboratories.

\section{Slide and sample collection}

Each laboratory collected 200 samples before and 200 after the training course. These consisted of a slide with thin and thick blood smears, a dried blood spot (DBS) and a form. After the slide examination the three components were sent to CISA Project. The form had the information about presence or absence of the parasite and in the positive cases the Plasmodium species.

\section{Assessing the impact of the intervention}

The impact of the intervention was evaluated through three essential points, namely testing, quality of slide preparation and performance of microscopy.

\section{Testing}

Before and after the training course it was applied the same written test of multiple choice questions to assess the trainees knowledge.

\section{Quality of slide preparation}

An expert microscopist evaluated the quality of preparation and staining of the blood films. After visual and microscopical examination, the slides were classified into three categories: good, satisfactory and bad. The criteria for this classification are in Table 1. 
Table 1 Blood smears classification criteria (Adapted from Kiggundu et al. [15])

\begin{tabular}{|c|c|c|}
\hline \multirow[t]{2}{*}{ Classification } & \multicolumn{2}{|l|}{ Criteria } \\
\hline & Thick blood smear & Thin blood smear \\
\hline \multirow[t]{4}{*}{ Bad } & $\begin{array}{l}\text { - Smear too big (diameter greater than } 1 \mathrm{~cm} \text { ) or } \\
\text { too small (diameter less than } 0.5 \mathrm{~cm} \text { ); }\end{array}$ & $\begin{array}{l}\text { - Smear too big (more than half of the slide) or too } \\
\text { small (smaller than } 0.5 \mathrm{~cm} \text { ); }\end{array}$ \\
\hline & $\begin{array}{l}\text { - Smear very close from the edge of the slide } \\
\text { (less than } 1 \mathrm{~cm} \text { ) which enables the use of } \\
\text { immersion oil; }\end{array}$ & $\begin{array}{l}\text { - Smear spread unevenly with patchy distribution, } \\
\text { streaky and with many tails (greasy slides or edge } \\
\text { of the spreader slide chipped); }\end{array}$ \\
\hline & $\begin{array}{l}\text { - Very thick smear (fine print cannot be read } \\
\text { through it); }\end{array}$ & $\begin{array}{l}\text { - Very thick smear that fine print cannot be read through } \\
\text { it or too thin with few red blood cells; }\end{array}$ \\
\hline & $\begin{array}{l}\text { - Poorly stained (red blood cells are not lysed and } \\
\text { parasites have a green, red, or blue colour). }\end{array}$ & $\begin{array}{l}\text { - Many red blood cells lysed and lightly stained cells } \\
\text { (red and white blood cells) and parasites. }\end{array}$ \\
\hline Satisfactory & $\begin{array}{l}\text { Smear well-made regarding size and location but } \\
\text { moderately stained (red blood cells are partially } \\
\text { lysed and parasites are lightly stained). }\end{array}$ & $\begin{array}{l}\text { Smear well-made regarding size and location but moderately } \\
\text { stained (red blood cells are partially lysed and parasites are } \\
\text { lightly stained). }\end{array}$ \\
\hline \multirow[t]{4}{*}{ Good } & $\begin{array}{l}\text { - Smear round in shape with a diameter of } \\
\text { approximately } 1 \mathrm{~cm} \text {; }\end{array}$ & $\begin{array}{l}\text { - Smear with the right dimension (half of the slide leaving } \\
\text { space for thick blood); }\end{array}$ \\
\hline & $\begin{array}{l}\text { - Smear at least } 1 \mathrm{~cm} \text { away from the edge of } \\
\text { the slide; }\end{array}$ & - Smear spread evenly (without patchy or streaky distribution); \\
\hline & $\begin{array}{l}\text { - Smear density that fine print can be read } \\
\text { through it; }\end{array}$ & - Smear density that fine print can just be read through it; \\
\hline & $\begin{array}{l}\text { - Smear with all of the red blood cells lysed, } \\
\text { and the malaria parasites are well-exposed } \\
\text { with a bluish pink coloration. }\end{array}$ & $\begin{array}{l}\text { - Smear with intact red blood cells and pink coloration, } \\
\text { intact white blood cells properly stained, and malaria } \\
\text { parasites are well-exposed with a bluish pink coloration. }\end{array}$ \\
\hline
\end{tabular}

\section{Performance of microscopy}

qPCR was used as the reference method to determine the performance of microscopy in malaria diagnosis. Each slide had a corresponding DBS. For the DNA extraction InstaGene ${ }^{\mathrm{TM}}$ Matrix $\left(\mathrm{Bio}^{\left.-\operatorname{Rad}^{\oplus}\right)}\right.$ was used and for the qPCR the PrimerDesign ${ }^{\mathrm{mm}}$ genesig Kit Genomes used according to manufacturer's instructions. Each sample was assessed for all Plasmodium species: Plasmodium falciparum, Plasmodium vivax, Plasmodium ovale and Plasmodium malariae.

\section{Data management and statistical analysis}

All data were entered in a database using Microsoft Office Excel $^{\oplus} 2010$ and analysed with IBM $^{\odot}$ SPSS $^{\bullet}$ Statistics 21. Performance of microscopy was defined as sensitivity and specificity, using qPCR as gold standard. To compare these measures, before and after the course, Pearson chisquare and Fisher's exact test, were applied as appropriate, and to compare the slides quality it was used Pearson chi-square test. The results of the written test were analysed by the Wilcoxon test. The $P$ value used as statistically significant was $<0.05$.

\section{Results}

\section{Written test}

The course attendance was 9, 8 and 11 participants for Bengo, Benguela and Luanda, respectively. Considering all three laboratories, there was a significant $(P<0.001)$ increase on the written test median score, from $52.5 \%$ to $65.0 \%$ of correct answers. The individual analysis by laboratory also showed an increase in the median score with statistical significance. These results are presented in Table 2.

\section{Quality of thick and thin blood smears}

973 slides (475 before and 498 after the course) were examined to evaluate the quality of thick and thin blood smears. In general, thick and thin smears were made in the same slide however $17.7 \%$ only had a thick smear. Before the course, Bengo delivered 200 slides of which 116 (58.0\%) did not have the thin smear. This percentage decreased to $20.8 \%$, after the course. Benguela delivered all samples with both smears and Luanda had $7.1 \%$ and $3.0 \%$ of slides without thin smear before and after the course, respectively. Considering all laboratories there was a significant increase in quality of both smears. In Bengo, the thick and thin smears had an increase in quality after the course but only the thin smear was significant $(P=0.003)$. Benguela registered a significant $(P<0.001)$ increase in quality of both smears. Luanda had a non-significant decrease in the quality of both smears. These results are presented in Table 3.

\section{Performance of microscopy}

To determine the performance (sensitivity and specificity) of microscopy taking $\mathrm{qPCR}$ as the reference method, 1,028 samples with microscopy results and DBS (516 pre-course and 512 post-course) were used. A total of 396, 240 and 392 samples from Bengo, Benguela and Luanda,were obtained respectively. Of the 1,028 
Table 2 Results of the written test before and after the training course

\begin{tabular}{|c|c|c|c|c|c|c|}
\hline \multirow[t]{2}{*}{ Laboratory } & \multirow[t]{2}{*}{$\mathrm{n}$} & \multicolumn{2}{|c|}{ Pre-course } & \multicolumn{2}{|c|}{ Post-course } & \multirow[b]{2}{*}{ P value* } \\
\hline & & Median score (\%) & Minimum-maximum (\%) & Median score (\%) & Minimum-maximum (\%) & \\
\hline Bengo & 9 & 45.0 & $20-55$ & 65.0 & $40-85$ & 0.006 \\
\hline Benguela & 8 & 57.5 & $45-70$ & 67.5 & $55-80$ & 0.038 \\
\hline Luanda & 11 & 55.0 & $20-75$ & 65.0 & $45-75$ & 0.003 \\
\hline Total & 28 & 52.5 & $20-75$ & 65.0 & $40-85$ & $<0.001$ \\
\hline
\end{tabular}

*Wilcoxon test.

samples, $242(23.5 \%)$ and $289(28.1 \%)$ were positive in qPCR and microscopy, respectively (Table 4).

Some laboratories increased sensitivity and specificity and others decreased but none of these variances were significant as shown in Table 5 . Benguela presented the higher values for specificity, $92.9 \%$ and $98.8 \%$ pre- and post-course, respectively. And for sensitivity the best precourse was Benguela (75.9\%) and post-course Luanda (75.0\%). Regarding species identification, Bengo identified one false $P$. vivax infection (which was not confirmed by qPCR) and one false negative in microscopy, which was positive for $P$. malariae using qPCR.

\section{Discussion}

It was presented the impact of a refreshment course, conducted in three health facilities from different provinces of Angola, in the improvement of malaria diagnosis. The effect of the intervention was evaluated by a written test, the quality of slide preparation and the performance of microscopy.

From the analysis of the written test is evident that it has an immediate impact on the workers knowledge, which is consistent with previous studies $[15,16]$. In the three laboratories, all technicians were asked to participate in the course, however, a very low participation rate was observed. The major reasons pointed were: schedule incompatibility, lack of financial reward on doing the course and the impossibility of laboratory closure in order to enable the participation of all technicians. The researchers believe that the laboratory staff felt uncomfortable on being evaluated and viewed this study as punitive and, therefore, good cooperation was very hard to accomplish. This reflected in difficulties in collecting all the necessary requests: information about routine diagnosis results by microscopy, thick and thin slides and DBS. It was collected all the three requests in $86.9 \%$ of

Table 3 Evaluation of the quality of thick and thin blood smears before and after the training course

\begin{tabular}{|c|c|c|c|c|c|c|c|c|c|}
\hline \multirow[t]{2}{*}{ Classification } & \multirow[t]{2}{*}{ Laboratory } & \multicolumn{3}{|c|}{ Thick blood smear } & \multicolumn{3}{|c|}{ Thin blood smear } & \multicolumn{2}{|c|}{ Slides without thin blood smea } \\
\hline & & Pre-course\% & Post-course \% & $P$ value* & Pre-course $\%$ & Post-course \% & $P$ value* & Pre-course $\%$ & Post-course\% \\
\hline & Bengo & $n=200$ & $n=197$ & & $n=200$ & $n=197$ & & & \\
\hline Bad & & 63.5 & 55.8 & 0.102 & 87.0 & 75.1 & $0.003^{\dagger}$ & 58.0 & 20.8 \\
\hline Satisfactory & & 32.0 & 41.7 & & 13.0 & 24.4 & & & \\
\hline \multirow[t]{2}{*}{ Good } & & 4.5 & 2.5 & & 0.0 & 0.5 & & & \\
\hline & Benguela & $n=107$ & $n=99$ & & $n=107$ & $n=99$ & & & \\
\hline Bad & & 32.7 & 9.0 & $<0.001$ & 74.7 & 18.2 & $<0.001$ & 0 & 0 \\
\hline Satisfactory & & 44.9 & 25.3 & & 20.6 & 31.3 & & & \\
\hline \multirow[t]{2}{*}{ Good } & & 22.4 & 65.7 & & 4.7 & 50.5 & & & \\
\hline & Luanda & $n=168$ & $n=202$ & & $n=168$ & $n=202$ & & & \\
\hline Bad & & 64.8 & 68.9 & 0.724 & 79.1 & 80.2 & 0.073 & 7.1 & 3.0 \\
\hline Satisfactory & & 29.2 & 25.7 & & 17.9 & 12.4 & & & \\
\hline \multirow[t]{2}{*}{ Good } & & 6.0 & 5.4 & & 3.0 & 7.4 & & & \\
\hline & Total & $n=475$ & $n=498$ & & $n=475$ & $n=498$ & & & \\
\hline Bad & & 57.0 & 51.8 & 0.003 & 81.5 & 65.8 & $<0.001$ & 26.9 & 9.4 \\
\hline Satisfactory & & 33.9 & 31.9 & & 16.4 & 20.9 & & & \\
\hline Good & & 9.1 & 16.3 & & 2.1 & 13.3 & & & \\
\hline
\end{tabular}

*Pearson chi-square.

${ }^{\dagger}$ Due to the small numbers the test was performed using only two categories: bad and satisfactory. 
Table 4 Matched-sample description of the data, comparing microscopy and qPCR

\begin{tabular}{|c|c|c|c|c|c|c|c|}
\hline & & \multirow{2}{*}{\multicolumn{2}{|c|}{$\begin{array}{c}\text { Total }(n=1028) \\
\text { PCR }\end{array}$}} & \multirow{2}{*}{\multicolumn{2}{|c|}{$\begin{array}{c}\text { Pre-course }(n=516) \\
\text { PCR }\end{array}$}} & \multirow{2}{*}{\multicolumn{2}{|c|}{$\begin{array}{l}\text { Post-course }(n=512) \\
\text { PCR }\end{array}$}} \\
\hline & & & & & & & \\
\hline & & Positive & Negative & Positive & Negative & Positive & Negative \\
\hline \multirow[t]{3}{*}{ Microscopy } & Positive & $165^{*}$ & 124 & $99^{*}$ & 57 & 66 & 67 \\
\hline & Negative & $77^{* *}$ & 662 & $44^{* *}$ & 316 & 33 & 346 \\
\hline & Total & 242 & 786 & 143 & 373 & 99 & 413 \\
\hline
\end{tabular}

${ }^{*}$ One false $P$. vivax infection in microscopy, which was $P$. falciparum (result from qPCR).

${ }^{* *}$ One false negative in microscopy, which was positive for $P$. malariae (result from qPCR).

the samples $(98.7 \%$ in Bengo, $82.0 \%$ in Benguela and $77.6 \%$ in Luanda).

In Ghana, Bates et al. [25] used a system of national supervisors and this was an important step for cooperation of the laboratory staff. However, the worker, responsible to collect the slides and forms was also seen as an outsider. The lack of communication between physicians and the laboratory staff, was also an issue which resulted in the less number of samples gathered before and after the course in Benguela. Nevertheless, Benguela was the one with the best median score after the course and had a significant improvement in the quality of both blood smears.

In the analysis of the quality of blood smear Luanda was the only one that registered a decrease. It could be explained by the different organization of the laboratory after the course; previously the majority of slides were made by one person but after the course all technicians, independently of participation in the course, started to do smears and staining. These findings prevent us from drawing any conclusion about the course impact in the quality of smear and accuracy of malaria diagnosis, for this particular laboratory.

One important aspect, pointed by WHO as crucial for achieving good competence and performance, is the motivation of the workers [8] for which good working conditions as adequate equipment and reagents are needed. The quality of malaria diagnostic, among other aspects, is more likely to be compromised by less motivated laboratory staff and the lack of adequate equipment undermines the laboratory performance [26]. The high percentage of slides lacking the thin blood smear raises concern about the relevance of a correct differentiation of Plasmodium species. In the present study, Bengo laboratory performed a thin smear in only $60.5 \%$ of the samples mainly due to the lack of methanol.

None of the laboratories registered a significant improvement in performance of malaria diagnosis. This failure may be explained by other factors than the training itself, for example in Benguela the specificity was already high before the training course. Ssekabira et al. [20] also found high specificity and sensitivity levels before the training course and after they did not find significant improvement in their study sites. Additionally, it is possible that the Luanda laboratory microscopy results were biased by a possible access of the technicians to previous RDTs results.

A high sensitivity is particularly important because of the risk of untreated cases of malaria, a potential lethal disease, and a high specificity is important for reducing the waste of limited resources, the increase of costs for drugs, unnecessary exposure of patients to the adverse effects of anti-malarial medication, for avoid drug resistance and also for prompting clinicians to look for other causes of illness $[6,15]$.

The decision to use qPCR as the study standard, instead expert microscopy (golden standard), was made considering the difficulty to make a correct diagnosis using poorly executed blood smears. A bad blood smear preparation can leave artefacts commonly mistaken for malaria parasites, which can lead to false-positive results, and false-negative results can appear if inadequate staining is performed. A bad preparation also increases the time and effort that it takes to read a blood smear [15].

Table 5 Diagnostic accuracy between microscopy and qPCR

\begin{tabular}{|c|c|c|c|c|c|c|}
\hline \multirow[t]{2}{*}{ Laboratory } & \multicolumn{3}{|c|}{ Sensitivity (\%) } & \multicolumn{3}{|c|}{ Specificity (\%) } \\
\hline & Pre-course & Post-course & $P$ value & Pre-course & Post-course & $P$ value \\
\hline Bengo & 42.3 & 57.1 & $0.375^{*}$ & 75.4 & 68.9 & $0.225^{*}$ \\
\hline Benguela & 75.9 & 62.5 & $0.344^{* *}$ & 92.9 & 98.8 & $0.118^{* *}$ \\
\hline Luanda & 72.9 & 75.0 & $0.979^{*}$ & 92.3 & 91.1 & $0.878^{*}$ \\
\hline Total & 68.5 & 66.7 & $0.869^{*}$ & 84.7 & 83.8 & $0.792^{*}$ \\
\hline
\end{tabular}

*Pearson chi-square.

**Fisher's exact test. 
The qPCR has advantages comparing to traditional PCR, being more rapid to perform and to obtain results. The one used in this study is a commercial kit but with a limitation, to the authors' knowledge there are no published studies comparing this kit with expert microscopy. Therefore validation of this kit is needed.

Another limitation of this study was the Hawthorne effect. Since the laboratory staff were aware they were under observation they may have improved their performance due to an increase of attention and not to the training course.

In conclusion, it was found an improvement in the knowledge and quality of blood smear preparation after the training course and so it is remark, at the laboratories, the importance of a continued programme training for technicians, combined to a quality control programme to assess the periodicity of new courses. Microscopy is the golden standard to malaria diagnosis, but it requires an expert microscopist to obtain high levels of sensitivity, so it is essential to invest in regular training and in the qualification of these professionals. In settings where is possible to implement other methods these could be considered as alternative or complement to microscopy. This study only measured the impact of the training course, but for a correct diagnosis it is important to have other conditions as the necessary equipment and reagents for staining and visualization, good working conditions, motivated and qualified personnel.

\section{Abbreviations}

ANMCP: Angola National Malaria Control Programme; CISA: Health Research Centre of Angola; DBS: Dried blood spot; PCR: Polymerase chain reaction qPCR: Real time PCR; RDT: Rapid diagnostic test; WHO: World Health Organization.

\section{Competing interests}

The authors declare that they have no competing interests.

\section{Authors' contributions}

MB was responsible for the coordination of all project, study design, and wrote the manuscript, SM and CF wrote the manuscript. CM carried out the analysis of the quality of blood smears and administered the training course. SM performed the statistical analysis. LB, MN, RS where responsible for the following of fieldwork in different hospitals. FF was responsible for the assistance in the training course. All authors read and approved the final draft of the manuscript.

\section{Acknowledgements}

The authors wish to acknowledge all the researchers and technicians who supported this study, namely from the CISA and from the three study sites. We wish to thank the local administration and the Angola National Malaria Control Programme, namely Carolina Ferreira. This work was funded by the promoters of CISA (Camões - Institute for Cooperation and Language, Calouste Gulbenkian Foundation, Bengo Provincial Government and the Ministry of Health of Angola) that have no participation on the design of the study and in the interpretation of the data.

\section{Author details}

${ }^{1}$ Health Research Centre of Angola (CISA), Caxito, Angola. ${ }^{2}$ Pediatric Hospital David Bernardino, Luanda, Angola. ${ }^{3}$ National Malaria Control Programme, Luanda, Angola. ${ }^{4}$ Faculty of Medicine Katyavala Bwila, Benguela, Angola. ${ }^{5}$ Lisbon School of Health Technology, Lisbon, Portugal.
Received: 14 May 2014 Accepted: 27 September 2014

Published: 18 November 2014

\section{References}

1. President's Malaria Initiative: Country Profile: Angola. http://www.pmi.gov/ docs/default-source/default-document-library/country-profiles/ angola_profile.pdf?sfursn=22.

2. Cosep Consultoria C, and ICF International: Angola Malaria Indicator Survey 2011. Calverton, Maryland: Cosep Consultoria, Consaúde and ICF Internationa; 2012.

3. WHO: World Malaria Report. Geneva: World Health Organization; 2013.

4. McKenzie FE, Sirichaisinthop J, Miller RS, Gasser RA Jr, Wongsrichanalai C: Dependence of malaria detection and species diagnosis by microscopy on parasite density. Am J Trop Med Hyg 2003, 69:372-376.

5. Wongsrichanalai C, Barcus MJ, Muth S, Sutamihardja A, Wernsdorfer WH: A review of malaria diagnostic tools: microscopy and rapid diagnostic test (RDT). Am J Trop Med Hyg 2007, 77:119-127.

6. Kahama-Maro J, D'Acremont V, Mtasiwa D, Genton B, Lengeler C: Low quality of routine microscopy for malaria at different levels of the health system in Dar es Salaam. Malar J 2011, 10:332.

7. Rowe AK, de Leon GF, Mihigo J, Santelli AC, Miller NP, Van-Dunem P. Quality of malaria case management at outpatient health facilities in Angola. Malar J 2009, 8:275.

8. WHO: Malaria Microscopy Quality Assurance Manual - Version 1. Geneva: World Health Organization; 2009.

9. Hanscheid T: Diagnosis of malaria: a review of alternatives to conventional microscopy. Clin Lab Haematol 1999, 21:235-245.

10. Ashraf S, Kao A, Hugo C, Christophel EM, Fatunmbi B, Luchavez J, Lilley K, Bell D: Developing standards for malaria microscopy: external competency assessment for malaria microscopists in the Asia-Pacific. Malar J 2012, 11:352

11. WHO: The Role of Laboratory Diagnosis to Support Malaria Disease Management. Focus on the use of Rapid Diagnostic Tests in Areas of High Transmission. Geneva: World Health Organization; 2006.

12. Payne D: Use and limitations of light microscopy for diagnosing malaria at the primary health care level. Bull World Health Organ 1988, 66:621-626.

13. Hanscheid T: Current strategies to avoid misdiagnosis of malaria. Clin Microbiol Infect 2003, 9:497-504

14. Zimmerman PA, Mehlotra RK, Kasehagen $\sqcup$, Kazura JW: Why do we need to know more about mixed Plasmodium species infections in humans? Trends Parasitol 2004, 20:440-447.

15. Kiggundu M, Nsobya SL, Kamya MR, Filler S, Nasr S, Dorsey G, Yeka A: Evaluation of a comprehensive refresher training program in malaria microscopy covering four districts of Uganda. Am J Trop Med Hyg 2011, 84:820-824

16. Nateghpour M, Edrissian G, Raeisi A, Motevalli-Haghi A, Farivar L, Mohseni G, Rahimi-Froushani A: The role of malaria microscopy training and refresher training courses in malaria control program in Iran during 2001-2011. Iran J Parasitol 2012, 7:104-109.

17. Namagembe A, Ssekabira U, Weaver MR, Blum N, Burnett S, Dorsey G, Sebuyira LM, Ojaku A, Schneider G, Willis K, Yeka A: Improved clinical and laboratory skills after team-based, malaria case management training of health care professionals in Uganda. Malar J 2012, 11:44.

18. Obare P, Ogutu B, Adams M, Odera JS, Lilley K, Dosoo D, Adhiambo C, Owusu-Agyei S, Binka F, Wanja E, Johnson J: Misclassification of Plasmodium infections by conventional microscopy and the impact of remedial training on the proficiency of laboratory technicians in species identification. Malar J 2013, 12:113.

19. Ngasala B, Mubi M, Warsame M, Petzold MG, Massele AY, Gustafsson LL, Tomson G, Premji Z, Bjorkman A: Impact of training in clinical and microscopy diagnosis of childhood malaria on antimalarial drug prescription and health outcome at primary health care level in Tanzania: a randomized controlled trial. Malar J 2008, 7:199.

20. Ssekabira U, Bukirwa H, Hopkins H, Namagembe A, Weaver MR, Sebuyira LM, Quick L, Staedke S, Yeka A, Kiggundu M, Schneider G, McAdam K, Wabwire-Mangen F, Dorsey G: Improved malaria case management after integrated team-based training of health care workers in Uganda. Am J Trop Med Hyg 2008, 79:826-833.

21. Di Santi SM, Kirchgatter K, Brunialti KC, Oliveira AM, Ferreira SR, Boulos M: PCR-based diagnosis to evaluate the performance of malaria reference centers. Rev Inst Med Trop Sao Paulo 2004, 46:183-187. 
22. Khairnar K, Martin D, Lau R, Ralevski F, Pillai DR: Multiplex real-time quantitative $P C R$, microscopy and rapid diagnostic immuno-chromatographic tests for the detection of Plasmodium spp: performance, limit of detection analysis and quality assurance. Malar J 2009, 8:284.

23. Tangpukdee N, Duangdee C, Wilairatana P, Krudsood S: Malaria diagnosis: a brief review. Korean J Parasitol 2009, 47:93-102.

24. WHO: Basic Malaria Microscopy. 2nd edition. Geneve: World Health Organization; 2010

25. Bates I, Bekoe V, Asamoa-Adu A: Improving the accuracy of malaria-related laboratory tests in Ghana. Malar J 2004, 3:38

26. Derua YA, Ishengoma DR, Rwegoshora RT, Tenu F, Massaga JJ, Mboera LE, Magesa SM: Users' and health service providers' perception on quality of laboratory malaria diagnosis in Tanzania. Malar J 2011, 10:78.

doi:10.1186/1475-2875-13-437

Cite this article as: Moura et al:: Impact of a training course on the quality of malaria diagnosis by microscopy in Angola. Malaria Journal 2014 13:437.

\section{Submit your next manuscript to BioMed Central and take full advantage of:}

- Convenient online submission

- Thorough peer review

- No space constraints or color figure charges

- Immediate publication on acceptance

- Inclusion in PubMed, CAS, Scopus and Google Scholar

- Research which is freely available for redistribution 